\title{
Anabases
}

ANABASES Traditions et réceptions de l'Antiquité

$24 \mid 2016$

Varia

\section{Brett M. Rogers et Benjamin Eldon Stevens (éd.), Classical Traditions in Science Fiction}

Catherine Valenti

\section{(2) OpenEdition}

1 Journals

Édition électronique

URL : http://journals.openedition.org/anabases/5791

DOI : 10.4000/anabases. 5791

ISSN : 2256-9421

Éditeur

E.R.A.S.M.E.

Édition imprimée

Date de publication : 10 novembre 2016

Pagination : 364-365

ISSN : 1774-4296

\section{Référence électronique}

Catherine Valenti, « Brett M. Rogers et Benjamin Eldon Stevens (éd.), Classical Traditions in Science Fiction", Anabases [En ligne], 24 | 2016, mis en ligne le 15 novembre 2016, consulté le 23 septembre 2020. URL : http://journals.openedition.org/anabases/5791 ; DOI : https://doi.org/10.4000/anabases 5791

Ce document a été généré automatiquement le 23 septembre 2020

(c) Anabases 


\title{
Brett M. Rogers et Benjamin Eldon Stevens (éd.), Classical Traditions in Science Fiction
}

\author{
Catherine Valenti
}

\section{RÉFÉRENCE}

Brett M. Rogers et Benjamin Eldon Stevens (éd.), Classical Traditions in Science Fiction, Oxford, Oxford University Press, 2015, $380 \mathrm{p}$.

23,49 livres/ isbn 978-0-19-022833-0

1 Professeurs assistants à Puget Sound University et à Bryn Mawr College, Brett M. Rogers et Benjamin Eldon Stevens ont réuni dans ce volume une douzaine de contributions consacrées à la réception de l'Antiquité dans les œuvres de sciencefiction, qu'il s'agisse de romans, de bandes dessinées, de films ou de séries télévisées.

2 Alors que la science-fiction, tournée vers l'avenir et mettant en scène des mondes futuristes, semble a priori très éloignée de l'Antiquité, les auteurs montrent dans l'introduction de l'ouvrage à quel point les références antiques irriguent au contraire les productions relevant de la science-fiction, y compris les plus contemporaines. Si l'on considère le Frankenstein de Mary Shelley, paru en 1818, comme le premier roman de science-fiction, on constate qu'il empruntait déjà aux mythes antiques : n'était-il pas sous-titré Le Prométhée moderne? L'émergence de la science-fiction, d'abord comme genre littéraire, parait effectivement contemporaine du retour de l'intérêt pour l'Antiquité à partir des XVII ${ }^{\mathrm{e}}$-XVIII ${ }^{\mathrm{e}}$ siècles.

3 Les contributions sont organisées en quatre grandes parties. La première explore les liens inattendus mais pourtant étroits entre les premiers écrits de science-fiction et les classiques antiques: Jesse Weiner montre ainsi que les poèmes épiques de Lucrèce et Lucien non seulement four-nissent les modèles de certains passages-clés du Frankenstein de Mary Shelley, mais nous aident également à comprendre l'intérêt de 
l'œuvre contemporaine pour les questions éthiques et scientifiques. Benjamin Eldon Stevens étudie quant à lui la réécriture de Virgile pratiquée par Jules Verne.

La deuxième partie examine l'influence de l'Antiquité sur les œuvres de science-fiction les plus récentes, celles des $\mathrm{xx}^{\mathrm{e}}$ et $\mathrm{xxi}^{\mathrm{e}}$ siècles. Il ne s'agit plus ici seulement de littérature, mais également de cinéma: Gregory S. Bucher analyse le film Forbidden Planet (Planète interdite), réalisé en 1956 par Fred McLeod Wilcox, et met en lumière les liens de ce long métrage à la fois avec la tragédie $\Subset$ dipe de Sophocle au v viècle avant J.C., et avec les conseils donnés par Aristote au iv ${ }^{e}$ siècle avant J.-C. dans sa Poétique. Dans sa contribution, Joel P. Christensen compare pour sa part les caractéristiques narratives et thématiques à l'œuvre à la fois dans l'lliade d'Homère et dans le Dune de Frank Herbert.

5 La troisième partie de l'ouvrage est plus particulièrement consacrée à l'influence antique dans les séries télévisées de science-fiction, des années 1960 à nos jours. Cette partie s'ouvre sur une contribution de George Kovacs qui explore l'utilisation des mythes grecs dans plusieurs épisodes de la série Star Trek (dont la diffusion aux ÉtatsUnis a commencé en 1966). Vincent Tomasso s'intéresse à une série plus récente, Battlestar Gallactica (diffusée entre 2004 et 2009), qui raconte les aventures, dans un avenir lointain, d'un groupe de réfugiés humains, partis en quête d'un nouvel astre où s'établir, et qui pratiquent une religion calquée sur celle des anciens Grecs. Au terme d'un périple à travers la galaxie, ils s'établissent sur une planète qui est en réalité la Terre, où ils vont fonder la civilisation telle que nous la connaissons: ce qui apparaissait comme un futur lointain se déroulait en réalité dans un passé reculé. Tomasso montre que les allusions à la religion grecque antique soulèvent des questions, d'ailleurs non résolues, sur les notions de « tradition » et de " progrès ".

6 La quatrième partie se focalise sur un thème central de la science-fiction contemporaine : l'utilisation d'« autres mondes » quels qu'ils soient - passés, futurs ou parallèles - pour penser des aspects importants voire controversés de notre propre univers. Marian Markins considère ainsi que la vision d'une Amérique tyrannique telle qu'elle est représentée dans la série Hunger Games s'inscrit en réalité dans une tradition ancienne qui présente la République romaine sous un jour négatif, les États-Unis se considérant plutôt comme les héritiers de l'empire romain. Certaines fictions flirtent quant à elles avec l'uchronie, présentant une histoire alternative, et interrogent du même coup les fondements de la civilisation occidentale : ainsi dans le «comics » Pax Romana de Jonathan Hickman, étudié par C. W. Marshall, l'Église catholique envoie-telle dans le passé des soldats chargés d'aider l'empereur Constantin à se débarrasser du paganisme, qui semble avoir triomphé dans un présent qui n'est pas le nôtre.

7 Au final, quelques grandes interrogations traversent ce volume : quelle est l'Antiquité représentée dans les œuvres de science-fiction, et la définition de cette Antiquité n'estelle pas largement tributaire des interprétations livrées au Moyen Âge et pendant les siècles qui ont suivi? Quelle(s) forme(s) aurait l'Antiquité sans ces réceptions successives? Surtout, les réceptions classiques dans la science-fiction ont-elles pour but de reconstituer l'Antiquité, ou plutôt de s'en débarrasser? Autant de questions auxquelles les contributions réunies dans ce volume apportent des éléments de réponse, sans doute destinés à être complétés par des études ultérieures. 


\section{AUTEURS}

\section{CATHERINE VALENTI}

Université Toulouse-Jean Jaurès (ut2j)

cvalenti@univ-tlse2.fr 